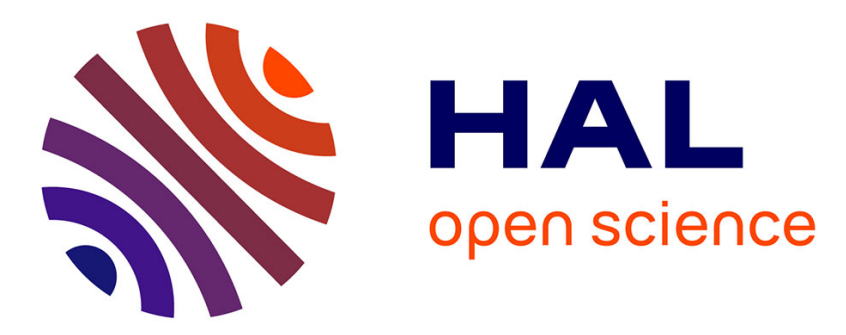

\title{
Effect of duodenal cannulation in sheep on the pattern of gastroduodenal electrical activity and digestive flow
}

\author{
C. Poncet, M. Ivan
}

\section{To cite this version:}

C. Poncet, M. Ivan. Effect of duodenal cannulation in sheep on the pattern of gastroduodenal electrical activity and digestive flow. Reproduction Nutrition Développement, 1984, 24 (6), pp.887-902. hal00898233

\section{HAL Id: hal-00898233 \\ https://hal.science/hal-00898233}

Submitted on 1 Jan 1984

HAL is a multi-disciplinary open access archive for the deposit and dissemination of scientific research documents, whether they are published or not. The documents may come from teaching and research institutions in France or abroad, or from public or private research centers.
L'archive ouverte pluridisciplinaire HAL, est destinée au dépôt et à la diffusion de documents scientifiques de niveau recherche, publiés ou non, émanant des établissements d'enseignement et de recherche français ou étrangers, des laboratoires publics ou privés. 
Reprod. Nutr. Dévelop., 1984, 24 (6), 887-902.

\title{
Effect of duodenal cannulation in sheep on the pattern of gastroduodenal electrical activity and digestive flow
}

\author{
C. PONCET, M. IVAN (1)
}

Laboratoire de la Digestion des Ruminants, I.N.R.A., Theix, 63122 Ceyrat, France.

Summary. The effects of duodenal cannulation in sheep on the patterns of electrical activity of the antrum and duodenum and on the duodenal flow of digesta were investigated. In addition to wire electrodes implanted on the antrum and on the ascending and transverse duodenum, groups of sheep were fitted with electromagnetic flow probes, simple ' $T$ '-shaped cannulas, ' $Y$ '-type reentrant cannulas or 'Ash'-type reentrant cannulas in the ascending duodenum. Recordings of electrical activity and duodenal digesta flow were carried out between 1 and 5 wk after surgery. It was found that the different surgical preparations affected the normal pattern of electrical activity, in the order : electromagnetic flow probe $<$ simple cannula $<$ Y-type reentrant cannula $<$ Ashtype reentrant cannula.

\section{Introduction.}

In studies of digestion and absorption in ruminant animals, simple or reentrant cannulation of different segments (primarily the ascending duodenum) of the small intestine is commonly employed. Although numerous cannulas have been developed, all of them are basically ' $T$ ' -shaped (Phillipson, 1952 ; Weller et al., 1971) or have a curved barrel (Ash, 1962) and are inserted into the small intestine by conventional surgical procedures (Brown et al., 1968 ; MacRae et al., 1973). Two of these cannulas are necessary in a reentrant system which diverts the flow of digesta to the animal's exterior. More recently, different systems of reentrant cannulation, which do not divert the flow of digesta to the exterior,

(1) Visiting scientist from the (present address) Animal Research Centre, Agriculture Canada, Ottawa, Ontario, Canada KIA OC6 (Contribution No. 1032). 
have been introduced (Wenham and Wyburn, 1980 ; Ivan and Johnston, 1981). However, little attention has been given to the effect of different cannulation systems on gastrointestinal motility, although an excellent radiological study of the effects of some cannulation methods on the movement of digesta in the small intestine has been recently published (Wenham and Wyburn, 1980). It has long been established that gastrointestinal cannulation does not grossly interfere with the digestion of food in sheep (Reid et al., 1961 ; MacRae et al., 1973 ; MacRae and Wilson, 1977; Sutton and Oldham, 1977). But a reduction in nitrogen balance (Unsworth and Stevenson, 1978) and an elevation in the serum copper level (MacRae and Wilson, 1977 ; Unsworth and Stevenson, 1978) in sheep with simple intestinal cannulae, as well as a reduction in wool growth in sheep with reentrant cannulae (MacRae and Wilson, 1977), indicate that some physiological changes may occur after cannulation. Also, a reduced forward flow (Harris and Phillipson, 1962) and a high backflow (Singleton, 1961) of digesta through duodenal reentrant cannulas were observed in early studies in sheep. Recently, gross abnormalities in motility and digesta flow were found in sheep equipped with an Ash-type reentrant cannula (Ash, 1962), but only minor alterations of motility and digesta flow were found in those equipped with a 'Hecker '-type reentrant cannula (Wenham and Wyburn, 1980). It is therefore evident that the magnitude of the physiological alteration depends on the cannulation method used.

The purpose of this study was to evaluate the effects of duodenal cannulation on the pattern of gastroduodenal electrical activity and flow of digesta in sheep equipped with Ash-type or Y-type (Ivan and Johnston, 1981) reentrant cannulas, with a simple cannula (Weller et al., 1971), or with an electromagnetic flow probe (Léveillé et al., 1979). Electromyography (Ruckebusch, 1970) was used to assess gastroduodenal motility in cannulated and normal sheep.

\section{Material and methods.}

Fourteen Texel wethers weighing from 35 to $45 \mathrm{~kg}$ were maintained on a daily ration consisting of $200-300 \mathrm{~g}$ of pelleted barley and $1.0-1.2 \mathrm{~kg}$ of good quality hay. The animals were housed in individual pens and had continuous access to water and trace mineralized salt blocks.

The sheep were fasted for $24 \mathrm{~h}$ before surgery. Laparotomy was performed on the right side approximately $2 \mathrm{~cm}$ posterior to the last rib using halothane anesthesia and aseptic conditions. In each animal, 1 or 2 groups of 3 electrodes, prepared from enamelled nickel chrome wire (Ruckebusch, 1970), were placed on the antral portion of the abomasum, duodenal bulb, ascending duodenum and transverse duodenum. The exact positions of the groups of electrodes relative to the pylorus are indicated for groups of sheep in figures $1,2,3,5$ and 7.

In addition to the electrodes, two of the sheep were equipped with an electromagnetic flow probe (Nycotron, type $1603 \mathrm{~W}$, Drammen, Norway) on the 
ascending duodenum $15 \mathrm{~cm}$ posterior to the pylorus, two with a simple T-shaped cannula (Weller et al., 1971), four with a Y-type reentrant cannula (Ivan and Johnston, 1981), and three with an Ash-type reentrant cannula (Ash, 1962). All the cannulas were placed in the ascending duodenum from 2 to $7 \mathrm{~cm}$ posterior to the pylorus ; the distal cannula of the Ash-type reentrant cannulation system was placed in the traverse duodenum immediately distal to the sigmoid flexure.

Recordings of electrical activity were taken between 1 and 5 weeks after surgery using an electroencephalograph machine (Reega VIII, Alvar, Paris). Each period of recording lasted for a minimum of $24 \mathrm{~h}$. Electromagnetic recordings of duodenal flow of digesta in the sheep equipped with an electromagnetic flow probe or reentrant cannulas were made simultaneously with the recordings of electrical activity. The electromagnetic flowmeter has been described previously (Poncet et al., 1977 ; Léveillé et al., 1979). The electromagnetic flow probe used with the Ash-type reentrant cannula was purchased from Nycotron, Drammen, Norway (type 1607, $9 \mathrm{~mm}$ internal diameter) and that used with the Y-type reentrant cannula was made in this laboratory $(12 \mathrm{~mm}$ internal diameter). The former was fitted between two barrels of the exterior part of the Ash-type reentrant cannula while the latter was inserted into the $\mathrm{Y}$-type reentrant cannula by replacing its circular valve.

\section{Results.}

Normal sheep. - The term 'normal sheep' refers to sheep equipped with electrodes and those equipped with an electromagnetic flow probe as opposed to animals with intestinal cannulas.

The pattern of gastroduodenal electrical activity was similar in all five normal sheep except that the number of migrating myoelectric complexes (MMC) per $24 \mathrm{~h}, 1-2$ wk after surgery, was considerably higher in the sheep equipped with the probe than in those equipped with electrodes only (table 1). However, the differences disappeared by 3-4 wk after surgery. The electrical activity at the distal antrum (fig. 1) consisted of bursts of spikes with a frequency of $5.8-7.5 / \mathrm{min}$. The amplitude of these spikes was not always the same; greater amplitude usually corresponded with the appearance of spiking activity at the duodenal bulb. The spiking activity at the distal antrum in the sheep equipped with the probe (fig. 2) was somewhat less uniform than in the other normal sheep (fig. 1).

There was a phase of well-defined irregular spiking activity (ISA) followed by a phase of regular spiking activity (RSA) and then a quiescent period (QP) which were well synchronized between the ascending and transverse duodenum (fig. 1 i). However, the phase of RSA at the ascending duodenum was rarely well defined (fig. 1A vs fig. 1B) although it was always coordinated with the appearance of the phase of RSA at the transverse duodenum. The frequency of bursts of spikes during the phase of RSA was higher at the transverse duodenum $(24 / \mathrm{min})$ than at the ascending duodenum $(11 / \mathrm{min})$.

During the phase of ISA, there were well defined isolated bursts of spikes, propagated from the bulb towards the transverse duodenum, each associated 


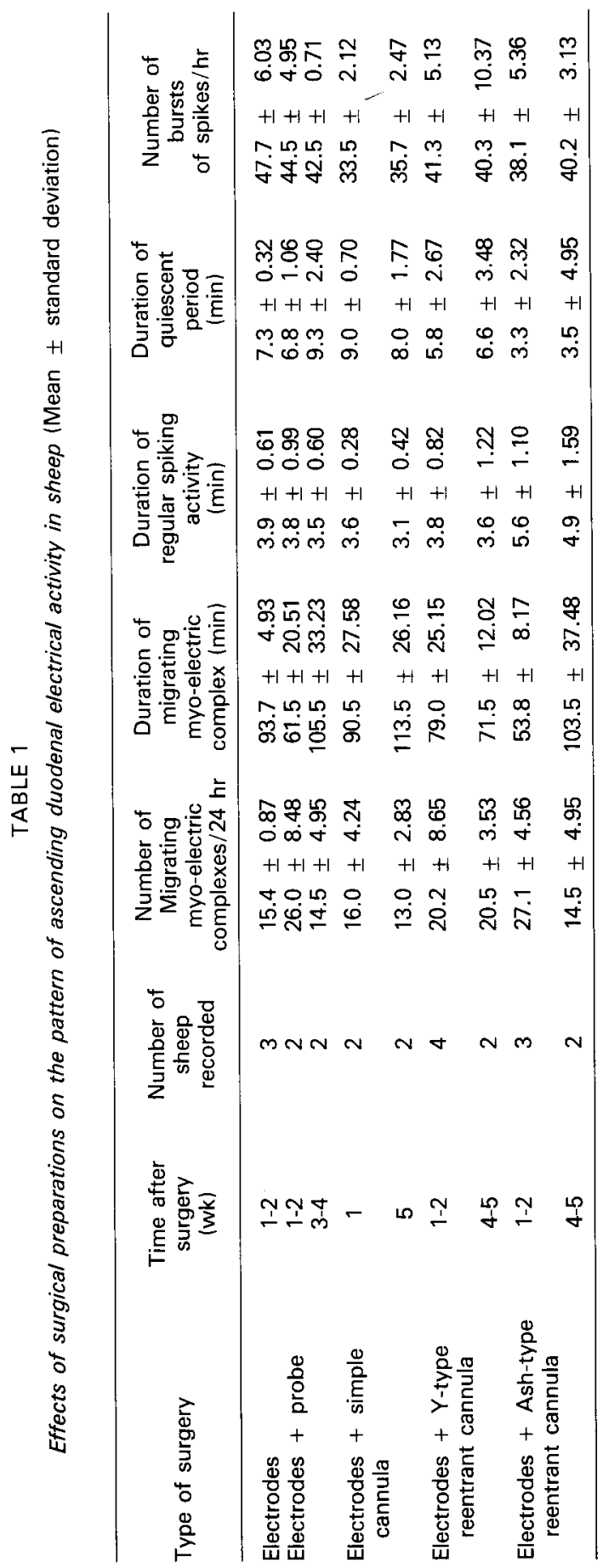



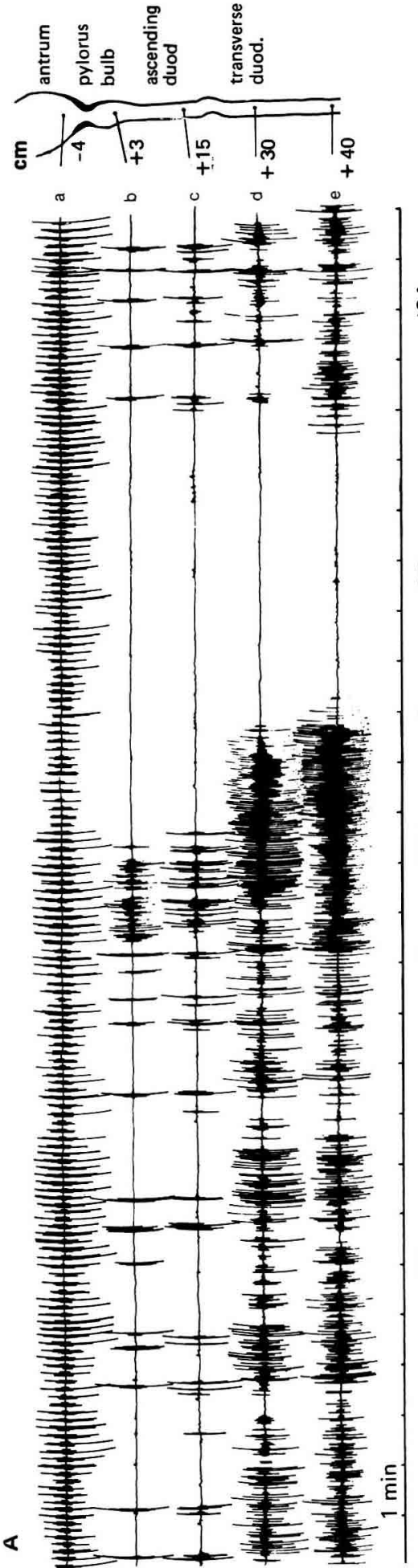

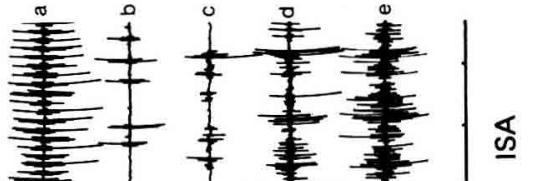

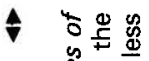

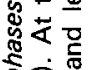
हरे 可京 3.8

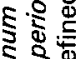
ब웡 8 政 ठ

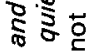
돈ำ ธิ㇒木 究 可产要 के 胥㗉

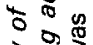
$\rightarrow$. 3ิ

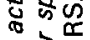

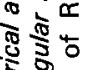
造 ठ을

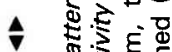
起 ॠ 농 के कर F亩 । -. 跣 林 ஸ் 

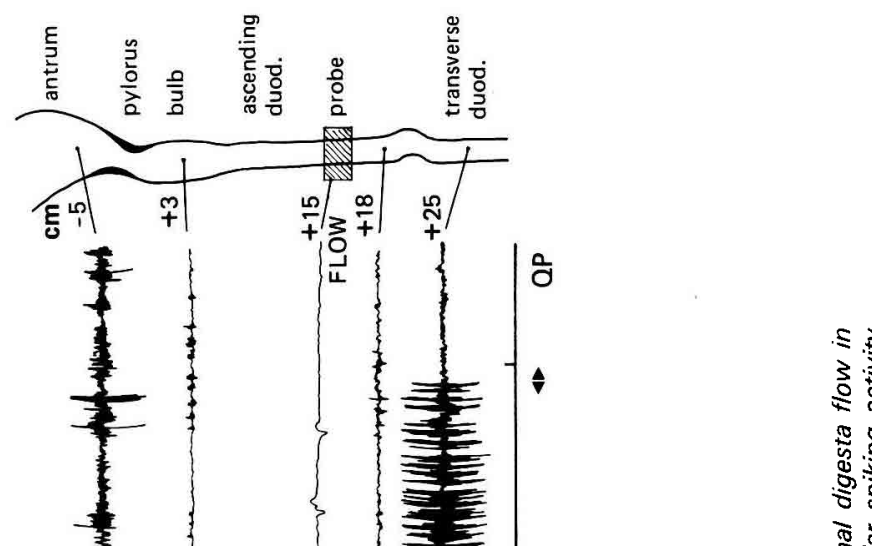


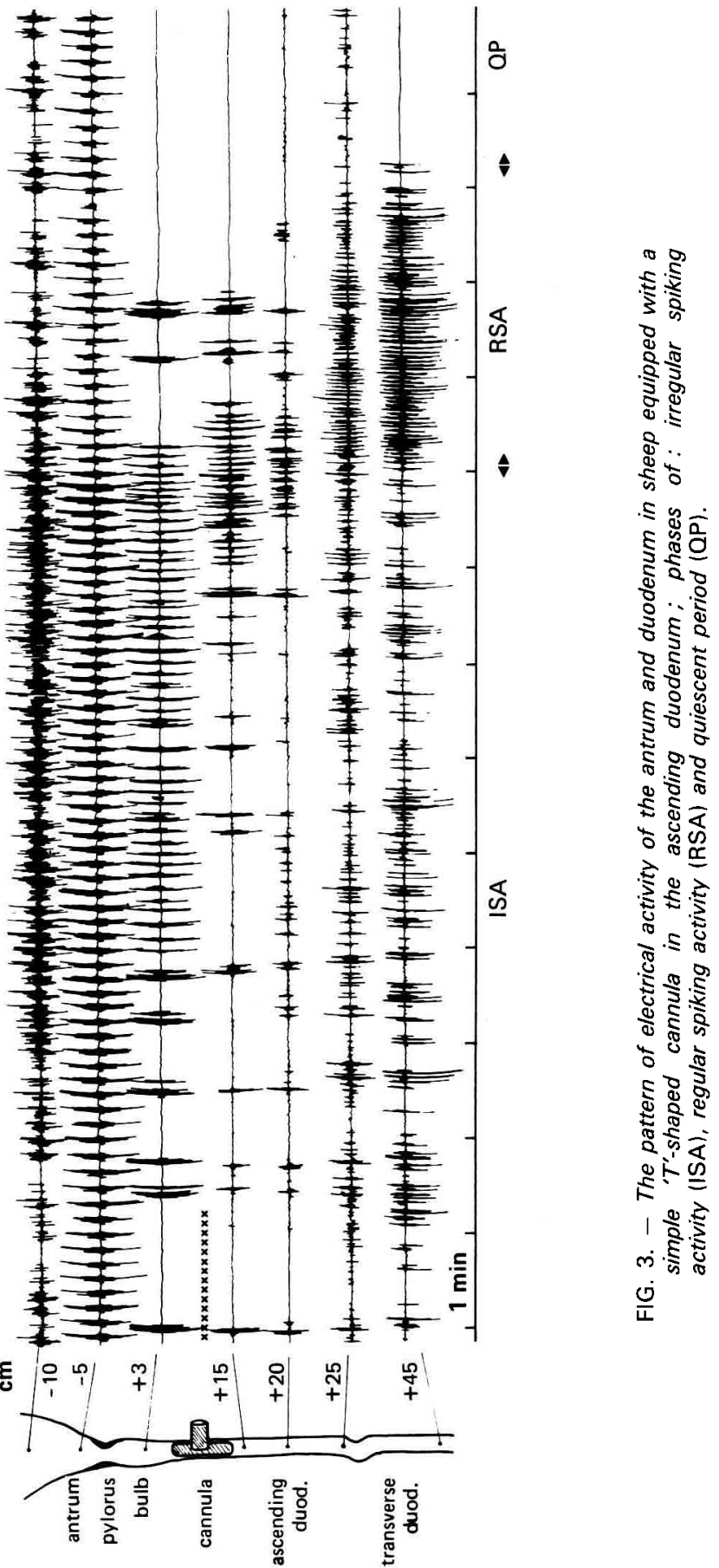


with a flow of $12-20 \mathrm{ml}$ of digesta in the ascending duodenum (fig. 2). Generally, each of these spikes yielded a series of 3-5 bursts at the transverse duodenum. During the period between these series of bursts there were also bursts of spikes that originated mainly at the transverse duodenum, some of them resulting in a small backflow of digesta in the ascending duodenum. There was some oscillation of unpropagated digesta in the ascending duodenum during the phase of RSA but no movement of digesta was apparent during the QP.

Sheep with a simple cannula. - The general pattern of occurrence and duration of the different phases of myoelectric activity in these sheep was similar to that in the normal sheep (table 1) although there was a notable decrease in the numbers of spike bursts. Furthermore, some differences were observed during the phases of ISA and RSA. Frequently, propagated bursts of spikes at the ascending duodenum originated from double bursts of spikes at the bulb (fig. 3 ). Also, in contrast to the normal propagation (fig. 4A), some bursts of spikes appeared simultaneously at the duodenal bulb (anterior to the cannula) and beyond the cannula (fig. 4B) while others appeared first beyond and then at the bulb (fig. 4C). In addition, the phase of RSA at the bulb was frequently well defined but abnormally long, appearing much in advance of that at the ascending duodenum beyond the cannula (fig. 3). There was dissociated electrical activity in the more distal portion of the duodenum at the end of the phase of RSA.

Sheep with a $Y$-type reentrant cannula. - About 1 month after surgery the number of $\mathrm{MMC} / 24 \mathrm{~h}$ was slightly greater in these sheep than in the normal (table 1). The amplitude of spikes at the distal antrum was very variable (fig. 5), increasing during periods of strong electrical activity at the duodenal bulb. There was also variation in the pattern of duodenal electrical activity among the sheep of this group : in one sheep no QP was apparent after the phase of RSA (fig. 5), whereas in the others such a phenomenon was not observed. In addition, the flow of digesta in some sheep occurred in groups of 2 to 4 small boluses, each separated by a backflow, but this irregularity generally disappeared with time after surgery. There was, however, occasional minor dissociation of electrical activity anterior and posterior to the cannula in all sheep, resulting in a flow of digesta during the phase of RSA.

During the phase of ISA in some sheep, propagated bursts of spikes appeared at the bulb in series of 3 to 9 (fig. 6A), followed by normal isolated bursts of spikes (fig. 6B), resulting in the flow of 3-17 ml of digesta, while some bursts of spikes originated beyond the cannula (fig. 6C) and resulted in the backflow of 1-4 $\mathrm{ml}$ of digesta. There were also groups of strong bursts of spikes that originated at the bulb but which were not always associated with the flow of digesta (fig. 6D).

Sheep with an Ash-type reentrant cannula. - The number of the MMC/24 h at 1-2 wk after surgery was higher in these sheep than in the normal sheep but the difference disappeared by 4-5 wk after surgery (table 1). The duration of the RSA phase was longer while the duration of the QP was shorter than in the normal sheep. This difference persisted even 4-5 after surgery.

Although the frequency of bursts of spikes at the antrum appeared to be normal the amplitude of these bursts was highly variable (fig. 7). A complete 

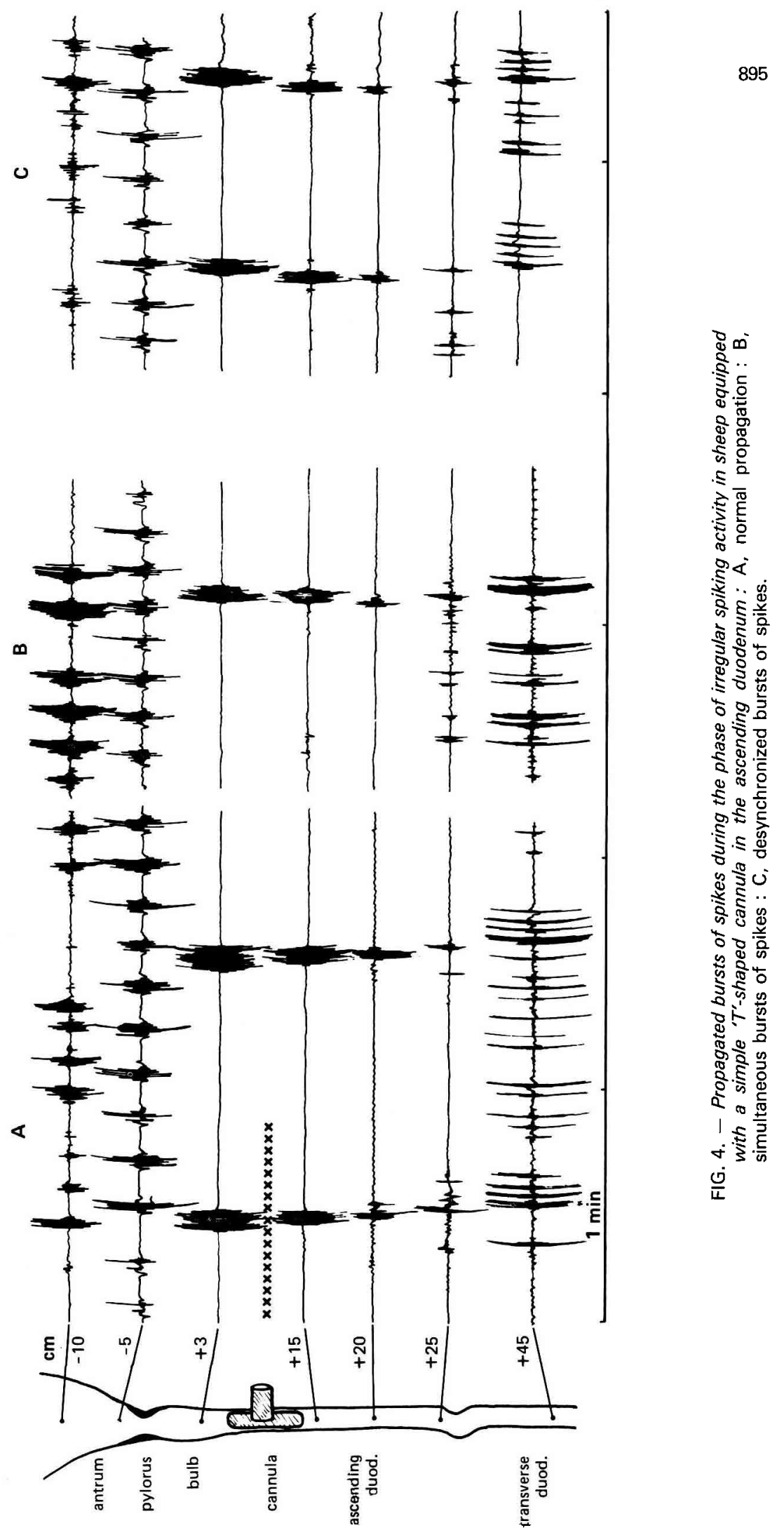


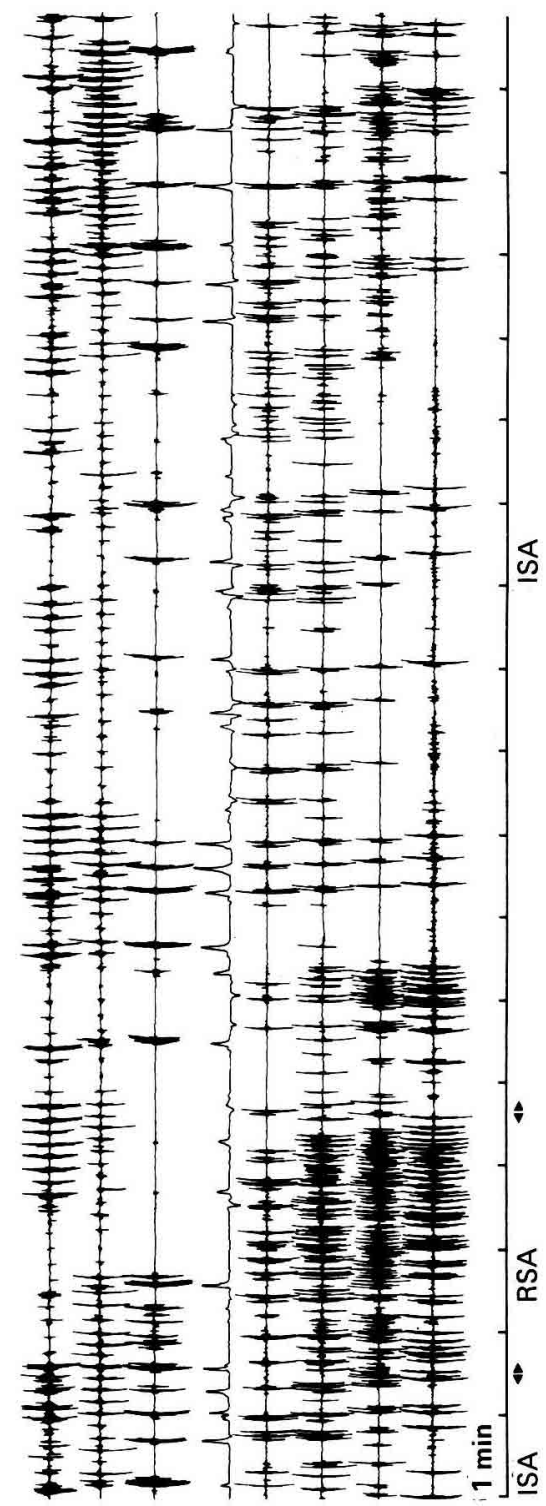




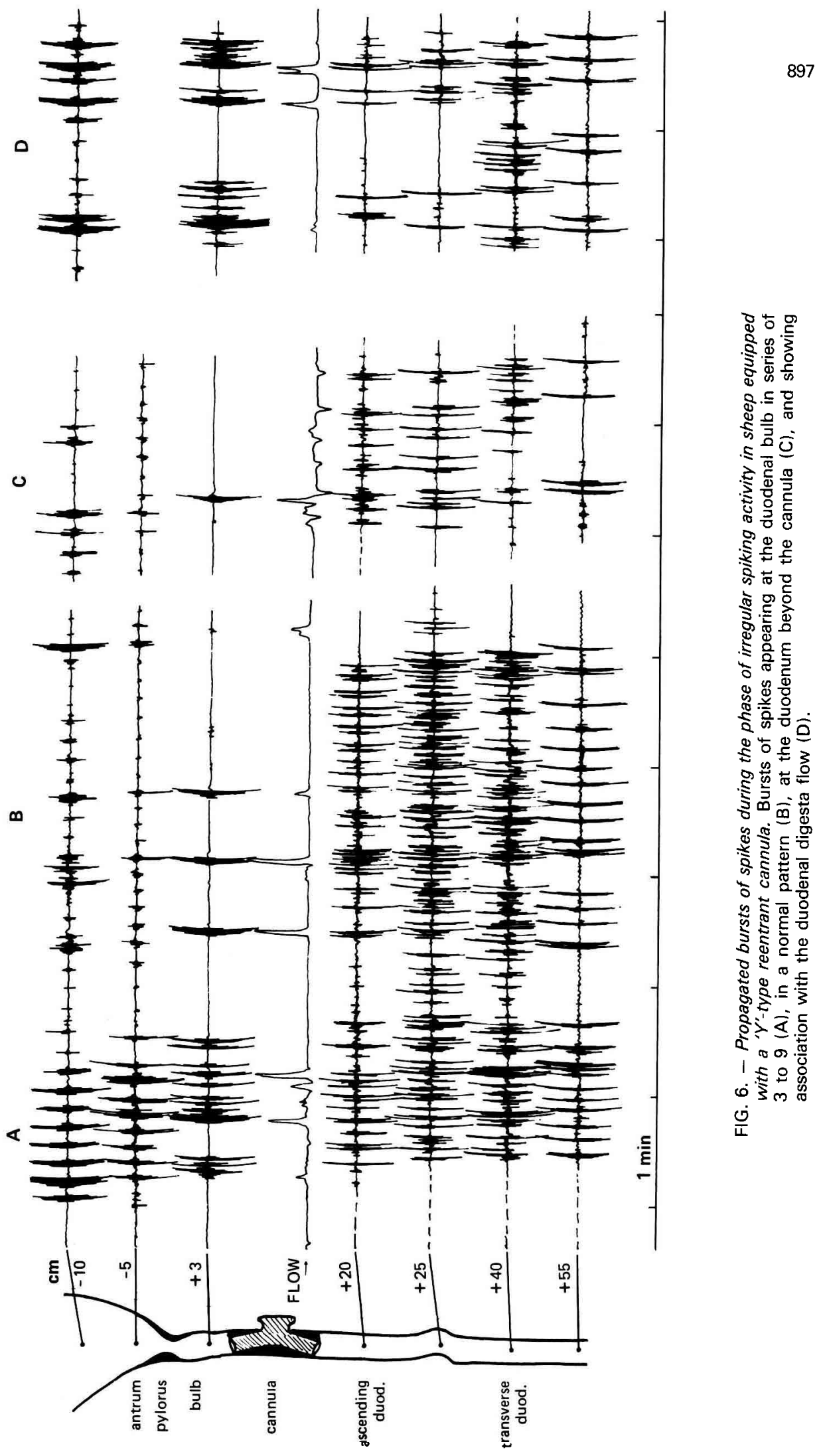




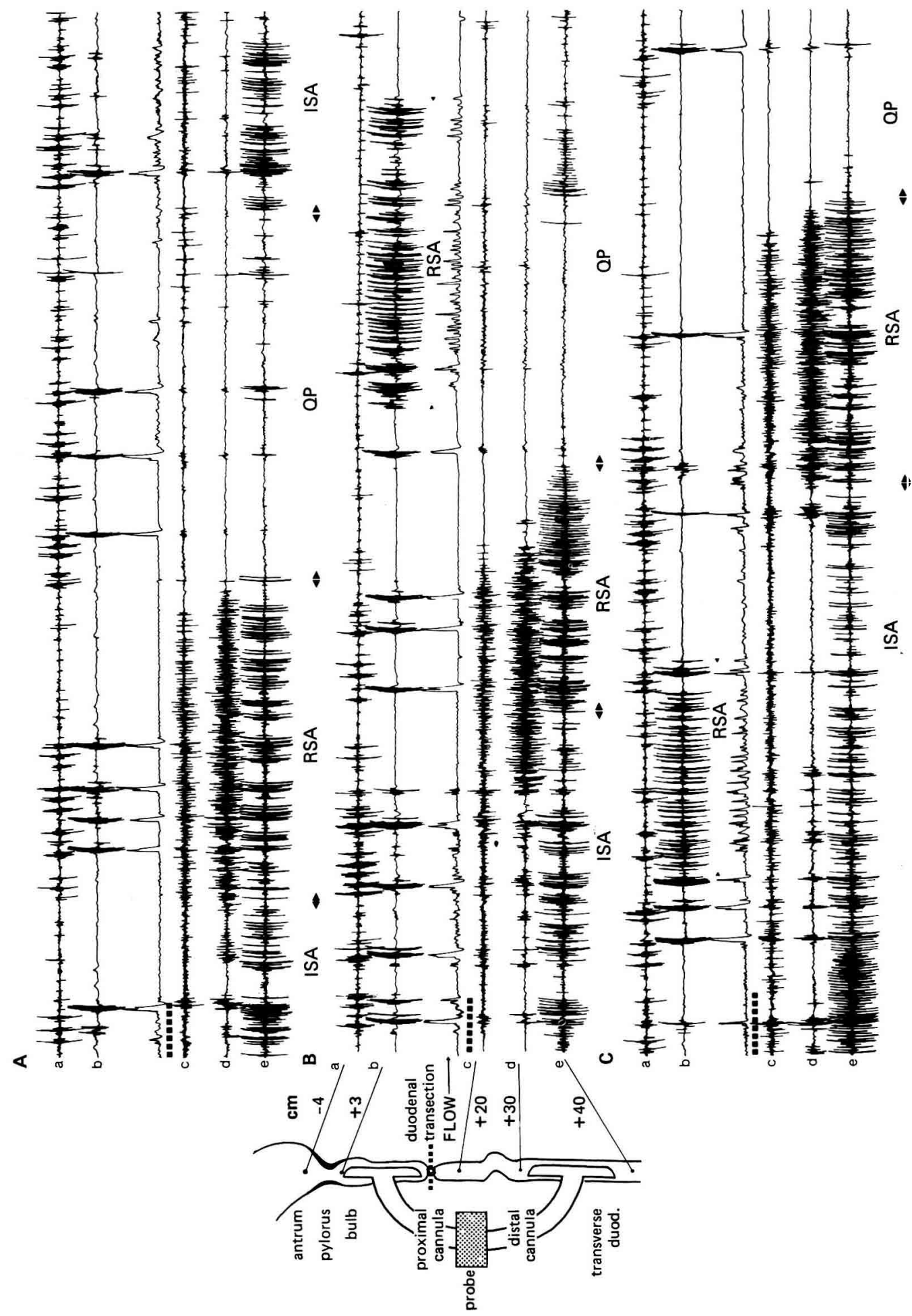

FIG. 7. - The relationship between gastroduodenal electrical activity and duodenal digesta flow in sheep equipped with an 'Ash'-type reentrant cannula. Desynchronized phase of regular spiking activity (A), evolved into a disturbed quiescent period beyond the duodenal transection (B) and then into a normal phase of irregular spiking activity $(\mathrm{C})$. 
dissociation of MMC in the duodenal segment proximal to the transection from that beyond the transection occurred in all sheep with the Ash-type reentrant cannula. Frequently, the phase of RSA appeared beyond the duodenal transection while there was a phase of ISA anterior to the transection, resulting in a flow of digesta through the cannula (fig. 7A). Although the phase of ISA in front of the transection continued, the phase of the RSA beyond the transection evolved into a somewhat disturbed QP. This was followed by a quite normal phase of ISA anterior to and beyond the transection. However, in other cases a phase of RSA appeared anterior to the transection during a QP (fig. 7B), or a phase of ISA (fig. 7C) beyond the transection. In both of the above cases there was apparent oscillation of digesta in the reentrant cannula during the phase of RSA. Generally, however, when a phase of ISA occurred simultaneously on both sides of the duodenal transection, bursts of spikes appeared to be propagated concurrent with changes in the flow of digesta.

\section{Discussion.}

The pattern of antral and duodenal electrical activity in the normal sheep equipped with electrodes only was similar in all aspects to that reported for conscious sheep (Ruckebusch, 1970 ; Bueno et al., 1975). Although for simplicity both the sheep equipped with electrodes only and those equipped with electrodes and the probe were identified as 'normal sheep', there was a small effect of the probe on the uniformity of the spiking electrical activity at the distal antrum. Since the propulsive spiking electrical activity at the duodenum was not affected by the probe and was well coordinated with the flow of digesta, we considered the above effect of the probe to be minor. There was no net duodenal flow of digesta in these sheep during the phase of RSA. This appears to be a normal phenomenon (Ruckebusch and Bueno, 1977a ; Wenham and Wyburn, 1980). The pattern of duodenal flow recorded with the probe was therefore used as a reference for the evaluation of duodenal flow in cannulated sheep.

The results of the present study indicated that the effect of the different surgical preparations on the normal pattern of electrical activity at the duodenum increased in the oder : electromagnetic flow probe $<$ simple cannula $<$ Y-type reentrant cannula $<$ Ash-type reentrant cannula. The fact that the simple cannula disturbed the normal pattern of electrical activity more than the probe was probably due to the effects of adhesion of the duodenum to the interior of the abdominal wall and of contact of the plastic cannula with the mucosa. These surgical modifications of the duodenum may have distorted and restricted contractions of smooth muscle in the region of the cannula. In contrast, the probe remained inside the abdominal cavity and did not touch the mucosa ; only a connecting electrical wire was exteriorized through the abdominal wall. Nevertheless, the disturbance of the normal pattern of electrical activity by the simple cannula was quite minor.

The effect of the comparatively new $Y$-type reentrant cannulation on the pattern of electrical activity at the antrum and duodenum was intermediate 
between that of the simple cannula and the Ash-type reentrant cannula. The amplitude of spikes at the distal antrum increased during the period of strong electrical activity at the duodenal bulb, perhaps in response to back pressure due to resistance caused by the rigid walls of the cannula. Although the pattern of digesta flow through the cannula was similar to that observed with the electromagnetic flow probe there was a somewhat higher frequency and volume of backflow. This higher backflow of digesta may have been due to the propulsive muscular activity that originated in the ascending duodenum posterior to the cannula (see fig. 6). There was, however, variation among the sheep with respect to the length of the duodenum between the pylorus and the cannula ; we consider that the ideal distance should be at least $4 \mathrm{~cm}$ to avoid interterence with the motile function of the pylorus and proximal duodenum (Ruckebusch and Bueno, 1977b). In one sheep with the cannula placed approximately $2 \mathrm{~cm}$ distal to the pylorus, gross deviations from the normal pattern of flow were observed. Wenham and Wyburn (1980) suggested that the segment of the duodenum between the pylorus and cannula should contain enough digesta to initiate a contraction and propel it through the cannula.

Gross abnormalities in the pattern of electrical activity at the antrum and duodenum, and in the pattern of the flow of digesta were observed in all three sheep fitted with the Ash-type reentrant cannula. This included a complete disorganization of MMC anterior and posterior to the transection of the ascending duodenum and abnormal backward movement of digesta. There was also great variation in the amplitude of spike bursts on the antrum; higher amplitude corresponded with the electrical spike activity at the duodenal bulb. Thus, it appears that a higher than normal force of contraction of the abomasum was required for periodic propulsion of digesta into the duodenum, possibly because of a high pressure in the duodenal bulb. Such forces would be required to overcome the resistance to digesta flow offered by the surface of the reentrant cannula. Furthermore the lack of coordinated muscular activity at the site of the preparation probably weakened the propulsive contractions of the proximal duodenum.

Wenham and Wyburn (1980) found gross abnormalities in the pattern of the flow of digesta in sheep equipped with Ash-type reentrant cannulae in the transverse duodenum, jejunum and ileum but only a minor modification of the flow when the cannula was placed in the ascending duodenum. However, their cannulation of the ascending duodenum probably involved placement of both the proximal and distal cannulas of the reentrant complex before the hepatic flexure. In contrast, our technique involved the more common placement of the proximal cannula in the ascending duodenum anterior to the transection and the distal cannula in the transverse duodenum. The placement of both cannulas into the ascending duodenum is difficult due to the shortness of this segment of the duodenum in most sheep.

The fitting of sheep with the simple duodenal cannula had no effect on the pattern of electrical activity at the distal antrum. However, the extent to which the other preparations disturbed the myoelectric activity seemed to be related to the length of the duodenum occupied by the cannulas or the electromagnetic 
flow probe. The lengths were $1 \mathrm{~cm}$ for the probe, $8 \mathrm{~cm}$ for the $Y$-type and $17 \mathrm{~cm}$ for the Ash-type reentrant cannulas. The performance of the Y-type cannula could probably be improved by decreasing its length to that of the simple cannula which was $6 \mathrm{~cm}$.

In conclusion, the results of the present study and the observations reported by Wenham and Wyburn (1980) demonstrate that simple intestinal cannulas cause minimal interference with the normal patterns of gastrointestinal motility and digesta flow in sheep. Moreover, results of studies of digestive physiology obtained with conventional reentrant cannulas should be treated with caution. Suitable designs of reentrant cannulas should be based on the simple cannula with a short intestinal tube. Such surgical preparations maintain the continuity of the intestine and lead to little disturbance to the muscular activity of the gut wall.

Recu en aoat 1982 Accepté en juillet 1984

Acknowledgements. - The authors wish to thank M. Léveillé for the construction of an electromagnetic flowmeter and for technical assistance in the use of the electromagnetic flow probe in sheep, J. Lefaivre for carrying out the surgical operations and L. L'Hotelier and $\mathrm{M}$. Fabre for care of the experimental animals. The authors also thank $\mathrm{C}$. Dardillat for his advice on the use of electromyography.

Résumé. Effet de la canulation duodénale sur l'activité myoélectrique gastroduodénale et le débit du contenu digestif chez le mouton.

Les effets de la canulation duodénale chez le mouton, sur l'activité myoélectrique de la caillette et du duodénum et sur les déplacements du contenu digestif dans le duodénum ont été décrits.

En plus d'électrodes implantées sur la partie antrale de la caillette et sur le duodénum ascendant et transverse, des groupes de 2 à 4 moutons ont été munis de capteurs débitmétriques électromagnétiques, de canules simples, de canules réentrantes en " $Y$ ", ou de canules réentrantes d'Ash. L'activité myoélectrique et le débit duodénal ont été enregistrés 1 semaine à 5 semaines après l'opération. Les différentes préparations chirurgicales permettant la mesure du débit intestinal affectent l'électromyographie gastroduodénale normale du mouton de façon variable : capteur électromagnétique < canule simple < canule réentrante en " $Y$ " < canule réentrante d'Ash.

En conséquence, les déplacements du contenu digestif dans le duodénum sont modifiés.

\section{References}

ASH R. W., 1962. Gastro-intestinal re-entrant cannulae for studies of digestion in sheep. Anim. Prod., 4, 309-312.

BROWN G. A., ARMSTRONG D. G., MacRAE J. C., 1968. The establishment in one operation of a cannulas into the rumen and reentrant cannulae into the duodenum and ileum of the sheep. Br. Vet. J., 124, 78-82. 
BUENO L., FIORAMONTI J., RUCKEBUSCH Y., 1975. Rate of flow of digesta and electrical activity of the small intestine in dogs and sheep. J. Physiol. (London), 249, 69-85.

HARRIS L. E., PHILLIPSON A. T., 1962. The measurement of the flow of food to the duodenum of sheep. Anim. Prod., 4, 97-116.

IVAN M., JOHNSTON D. W., 1981. Reentrant cannulation of the small intestine in sheep: cannula and surgical method. J. anim. Sci, 52, 849-856.

LÉVEILLÉ M., PONCET C., DARDILLAT C., 1979. Characteristics of an electromagneticflowmeter specially built to measure intestinal flow in sheep. Ann. Rech. vét., 10. 497-499.

MacRAE J. C., REID C. S. W., DELLOW D. W., WYBURN R. S., 1973. Caecal cannulation in the sheep. Res. Vet. Sci, 14, 78-85.

MacRAE J. C., WILSON S., 1977. The effects of various forms of gastro-intestinal cannulation on digestive measurements in sheep. Br. J. Nutr., 38, 65-71.

PHILLIPSON A. T., 1952. The passage of digesta from the abomasum of sheep. J. Physiol. (London), 116, 84-97.

PONCET C., DIMOVA E., LÉVEILLÉ M., DARDILLAT C., 1977. Permanent recording of duodenal flow in sheep. Ann. Biol. anim. Bioch. Biophys., 17, 515-522.

REID R. L., SHELTON D. C., WELCH J. A., 1961. In A. J. G. BARNET, R. L. REID, Reaction in the rumen. Edward Arnold, London. p. 37.

RUCKEBUSCH Y., 1970. The electrical activity of the digestive tract of the sheep as an indication of the mechanical events in various regions. J. Physiol. London, 210, 857.882.

RUCKEBUSCH Y., BUENO L., 1977a. Migrating myoelectrical complex of the small intestine. Gastroentology, 73, 1309-1314.

RUCKEBUSCH Y., BUENO L., 1977b. Origin of migrating myoelectric complex in sheep. Am. $J$. Physiol., 233, E483-E487.

SINGLETON A. G., 1961. The electromagnetic measurement of the flow of digesta through the duodenum of the goat and the sheep. $J$. Physiol. (London), 155, 134-147.

SUTTON J. D., OLDHAM J. D., 1977 . Feed evaluation by measurement of sites of digestion in cannulated ruminants. Proc. Nutr. Soc., 36, 203-209.

UNSWORTH E. F., STEVENSON M. H., 1978. The effects of gastro-intestinal surgery on the intake and digestibility of pelleted dried grass by sheep. Record Agric. Res., 26, 101-104.

WELLER R. A., PILGRIM A. F., GRAY F. V., 1971. Level of food intake and the passage of markers and nitrogen along the alimentary tract of sheep. Br. J. Nutr., 26, 487-497.

WENHAM G., WYBURN R. S., 1980. A radiological investigation of the effects of cannulation on intestinal motility and digesta flow in sheep. J. agric. Sci., Camb., 95, 539-546. 